\title{
PX-12-induced HeLa cell death is associated with oxidative stress and GSH depletion
}

\author{
HYE RIM SHIN, BO RA YOU and WOO HYUN PARK \\ Department of Physiology, Medical School, Research Institute for Endocrine Sciences, \\ Chonbuk National University, Jeonju 561-180, Republic of Korea \\ Received March 26, 2013; Accepted October 11, 2013
}

DOI: $10.3892 / \mathrm{ol} .2013 .1637$

\begin{abstract}
PX-12, as an inhibitor of thioredoxin (Trx), has antitumor activity. However, little is known about the toxicological effect of PX-12 on cervical cancer cells. In the present study, the growth inhibitory effects of PX-12 on HeLa cervical cancer cells in association with reactive oxygen species (ROS) and glutathione (GSH) levels were investigated. Based on MTT assays, PX-12 inhibited the growth of HeLa cells with an $\mathrm{IC}_{50}$ value of $\sim 7 \mu \mathrm{M}$ at $72 \mathrm{~h}$. DNA flow cytometry analysis indicated that 5 and $10 \mu \mathrm{M}$ PX-12 significantly induced a G2/M phase arrest of the cell cycle. PX-12 also increased the number of dead cells and annexin V-fluorescein isothiocyanate-positive cells, which was accompanied by the loss of mitochondrial membrane potential. All the investigated caspase inhibitors significantly rescued certain cells from PX-12-induced HeLa cell death. With respect to ROS and GSH levels, PX-12 increased ROS levels (including $\mathrm{O}_{2}{ }^{\circ}$ ) in HeLa cells and induced GSH depletion. N-acetyl cysteine markedly reduced the levels of $\mathrm{O}_{2}{ }^{--}$in PX-12-treated HeLa cells, and prevented apoptotic cell death and GSH depletion in these cells. By contrast, L-buthionine sulfoximine intensified
\end{abstract}

Correspondence to: Professor Woo Hyun Park, Department of Physiology, Medical School, Chonbuk National University, Jeonju 561-180, Republic of Korea

E-mail: parkwh71@chonbuk.ac.kr

Abbreviations: ROS, reactive oxygen species; Trx, thiore doxin; GSH, glutathione; Z-VAD-FMK, benzyloxycarbonyl-Val-AlaAsp-fluoromethylketone; Z-DEVD-FMK, benzyloxycarbonylAsp-Glu-Val-Asp-fluoromethylketone; Z-IETD-FMK, benzyl oxycarbonyl-Ile-Glu-Thr-Asp-fluoromethylketone; Z-LEHD-FMK, benzyloxycarbonyl-Leu-Glu-His-Asp-fluoromethylketone; NAC, $\mathrm{N}$-acetyl cysteine; BSO, L-buthionine sulfoximine; MMP, mitochondrial membrane potential; MTT, 3-(4,5-dimethylthiazol2-yl)-2,5-diphenyltetrazolium bromide; FITC, fluorescein isothiocyanate; PI, propidium iodide; $\mathrm{H}_{2}$ DCFDA, 2',7'dichlorodihydrofluorescein diacetate; DHE, dihydroethidium; CMFDA, 5-chloromethylfluorescein diacetate

Key words: PX-12, reactive oxygen species, thioredoxin, cell death, HeLa cell death and GSH depletion in PX-12-treated HeLa cells. To conclude, this is the first study to demonstrate that PX-12 inhibits the growth of HeLa cells via G2/M phase arrest, as well as inhibiting apoptosis; the effect was associated with intracellular increases in ROS levels and GSH depletion.

\section{Introduction}

Reactive oxygen species (ROS) are highly reactive oxygen free radicals or non-radical molecules, which include hydrogen peroxide $\left(\mathrm{H}_{2} \mathrm{O}_{2}\right)$, superoxide anion $\left(\mathrm{O}_{2}^{-}\right)$and hydroxyl radical ('OH) (1). These molecules regulate a number of cellular events, including transcription factor activation, gene expression, differentiation and cell proliferation $(2,3)$. ROS are mainly formed as by-products of the respiratory chain during oxidative phosphorylation in the form of $\mathrm{O}_{2}{ }^{--}$or are specifically produced by oxidases, such as nicotine adenine diphosphate (NADPH) oxidase, xanthine oxidase and arachidonic acid oxygenases (4). Excessive ROS production induces cellular damage and death $(5,6)$. Therefore, there are various antioxidants and systems to control excessive ROS levels.

Thioredoxin $(\operatorname{Tr} x)$ is a low molecular weight (10- to $12-\mathrm{kDa}$ ) redox protein (7), which affects cell growth and proliferation by regulating the redox status in cells (8). Trx has two main isoforms: The cytosolic form, Trx-1, and the mitochondrial form, Trx-2 (9). These Trxs are reduced back by Trx reductase and NADPH following the reduction of oxidative target proteins $(10,11)$. It has been reported that $\operatorname{Tr} x-1$ is implicated in cell survival, tumor development, angiogenesis and chemoresistance $(12,13)$. Numerous studies have demonstrated that the overexpression of Trx occurs in a variety of cancer types, including gastric and lung cancers $(8,14)$. PX-12 (1-methylpropyl 2-imidazolyl disulfide) is an irreversible Trx-1 inhibitor, which has antitumor properties (15). PX-12 decreased the activity of Trx-1 by thioalkylating the critical cysteine residue (Cys73) in this protein or by increasing the dimerization of its oxidative form. It has also been reported that PX-12 decreases hypoxia-inducible factor-1 $\alpha$ transactivation and vascular endothelial growth factor $(16,17)$. Therefore, PX-12 has been clinically tested in colorectal, lung and pancreatic cancers $(18,19)$.

Cervical cancer is a major cause of mortality in females worldwide. Its carcinogenesis is associated with excessive inflammation mediated by ROS. An increase in Trx-1 levels 
has been observed in cervical cancer patients compared with a control group (20). However, little is known about the cellular effect of PX-12 in cervical cancer. PX-12-induced cell death in cervical cancer cells may be toxicologically attractive in relation to intracellular ROS levels. Therefore, in the present study, the effects of PX-12 on cell growth and death were investigated in human cervical adenocarcinoma HeLa cells. The effects of various caspase inhibitors (pan-caspase and caspase-3, -8 and -9), N-acetyl cysteine (NAC; a well known antioxidant) and L-buthionine sulfoximine [BSO; an inhibitor of glutathione (GSH) synthesis] were also evaluated in PX-12-treated HeLa cells with respect to cell growth, cell death and ROS and GSH levels.

\section{Materials and methods}

Cell culture. Human cervical adenocarcinoma HeLa cells were obtained from the American Type Culture Collection (Manassas, VA, USA) and maintained in a humidified incubator containing $5 \% \mathrm{CO}_{2}$ at $37^{\circ} \mathrm{C}$. The HeLa cells were cultured in RPMI-1640 (Sigma-Aldrich, St. Louis, MO, USA) supplemented with $10 \%$ fetal bovine serum (Sigma-Aldrich) and $1 \%$ penicillin-streptomycin (Gibco BRL, Grand Island, NY, USA). The cells were routinely grown in 100-mm plastic tissue culture dishes (Nunc, Roskilde, Denmark) and harvested with a solution of trypsin-EDTA while in a logarithmic phase of growth.

Reagents. PX-12 was purchased from Tocris Bioscience (Bristol, UK) and was dissolved in dimethyl sulfoxide (DMSO; Sigma-Aldrich) at $100 \mathrm{mM}$ as a stock solution. The pan-caspase inhibitor benzyloxycarbonyl-Val-Ala-Asp-fluoromethylketone (Z-VAD-FMK), caspase-3 inhibitor benzyloxycarbonyl-Asp-Glu-Val-Asp-fluoromethylketone (Z-DEVD-FMK), caspase-8 inhibitor benzyloxycarbonyl-Ile-Glu-Thr-Asp-fluoromethylketone (Z-IETD-FMK) and caspase-9 inhibitor benzyloxycarbonyl-Leu-Glu-His-Asp-fluoromethylketone (Z-LEHD-FMK) were obtained from R\&D Systems Inc. (Minneapolis, MN, USA) and were dissolved in DMSO at $10 \mathrm{mM}$ to serve as stock solutions. NAC and BSO were obtained from Sigma-Aldrich. NAC was dissolved in $20 \mathrm{mM}$ HEPES buffer (pH 7.0) and BSO was dissolved in water. Based on previous studies $(21,22)$, cells were pretreated with $15 \mu \mathrm{M}$ caspase inhibitors, $2 \mathrm{mM}$ NAC or $10 \mu \mathrm{M}$ BSO for $1 \mathrm{~h}$ prior to treatment with PX-12. DMSO $(0.2 \%)$ was used as a control vehicle and it did not affect cell growth or death.

Growth inhibition assay. The effect of PX-12 on cell growth was determined by measuring 3-(4,5-dimethylthiazol-2-yl)-2,5-diphenyltetrazolium bromide (MTT; Sigma-Aldrich) absorbance in living cells as described previously (23). In brief, $1 \times 10^{4}$ cells/well were seeded in 96-well microtiter plates (Nunc). Following exposure to the designated doses of PX-12 for the indicated times, MTT solution [20 $\mu \mathrm{l}$ : $2 \mathrm{mg} / \mathrm{ml}$ in phosphate-buffered saline (PBS)] was added to each well. The plates were incubated for $3 \mathrm{~h}$ at $37^{\circ} \mathrm{C}$. Medium was withdrawn from the plates by pipetting and $200 \mu \mathrm{l}$ DMSO was added to each well to solubilize the formazan crystals. The optical density was measured at $570 \mathrm{~nm}$ using a microplate reader (Synergy ${ }^{\mathrm{TM}}$ 2, BioTek Instruments Inc., Winooski, VT, USA). The cell population was visualized under a light microscope at x400 magnification (FLoid ${ }^{\circledR}$ Cell Imaging Station, Life Technologies Corporation, Carlsbad, CA, USA).

Cell cycle and sub-G1 cell analysis. Cell cycle and sub-G1 cell analysis were determined by propidium iodide (PI, Ex/Em=488/617 nm; Sigma-Aldrich) staining as described previously (24). In brief, $1 \times 10^{6}$ cells in a $60-\mathrm{mm}$ culture dish (Nunc) were incubated with the designated doses of PX-12 for $72 \mathrm{~h}$. Total cells, including floating cells, were then washed with PBS and fixed in $70 \%$ (v/v) ethanol. Cells were washed again with PBS, then incubated with PI $(10 \mu \mathrm{g} / \mathrm{ml})$ with simultaneous RNase treatment at $37^{\circ} \mathrm{C}$ for $30 \mathrm{~min}$. Cellular DNA content was measured using a FACStar flow cytometer (Becton Dickinson, Franklin Lakes, NJ, USA) and analyzed using Lysis II and CellFit software (Becton Dickinson).

Annexin V-fluorescein isothiocyanate (FITC)/PI staining for the detection of cell death. Apoptotic cell death was determined by staining cells with annexin V-FITC $(\mathrm{Ex} / \mathrm{Em}=488 / 519 \mathrm{~nm}$; Invitrogen Life Technologies, Camarillo, CA, USA) as described previously (25). In brief, $1 \times 10^{6}$ cells in a $60-\mathrm{mm}$ culture dish were incubated with the designated doses of PX-12 for $72 \mathrm{~h}$ with or without $15 \mu \mathrm{M}$ each caspase inhibitor, $2 \mathrm{mM}$ NAC or $10 \mu \mathrm{M}$ BSO. Cells were washed twice with cold PBS and then resuspended in $500 \mu \mathrm{l}$ binding buffer $[10 \mathrm{mM}$ HEPES/NaOH (pH 7.4), $140 \mathrm{mM} \mathrm{NaCl}$ and $\left.2.5 \mathrm{mM} \mathrm{CaCl}_{2}\right]$ at a concentration of $1 \times 10^{6}$ cells $/ \mathrm{ml}$. Annexin V-FITC (5 $\left.\mu \mathrm{l}\right)$ and PI $(1 \mu \mathrm{g} / \mathrm{ml})$ were then added and the cells were analyzed with the FACStar flow cytometer. Viable cells were negative for PI and annexin $\mathrm{V}$, apoptotic cells were positive for annexin $\mathrm{V}$ and negative for PI, whereas late apoptotic dead cells exhibited high annexin V and PI labeling. Non-viable cells that underwent necrosis, were positive for PI and negative for annexin V.

Measurement of the mitochondrial membrane potential $(M M P)$. MMP was measured by a rhodamine 123 fluorescent dye $(E x / E m=485 / 535 \mathrm{~nm}$; Sigma-Aldrich) as described previously $(25,26)$. In brief, $1 \times 10^{6}$ cells in a $60-\mathrm{mm}$ culture dish were incubated with the designated doses of PX-12 for $72 \mathrm{~h}$ with or without $15 \mu \mathrm{M}$ each caspase inhibitor, $2 \mathrm{mM}$ NAC or $10 \mu \mathrm{M}$ BSO. Cells were washed twice with PBS and incubated with rhodamine $123(0.1 \mu \mathrm{g} / \mathrm{ml})$ at $37^{\circ} \mathrm{C}$ for $30 \mathrm{~min}$. Rhodamine 123 staining intensity was determined using the FACStar flow cytometer. The cells that were rhodamine 123-negative were indicated to have lost MMP.

Detection of intracellular ROS levels. Intracellular ROS levels were detected using an oxidation-sensitive fluorescent probe dye, 2',7'-dichlorodihydrofluorescein diacetate $\left(\mathrm{H}_{2} \mathrm{DCFDA}\right.$; $\mathrm{Ex} / \mathrm{Em}=495 / 529 \mathrm{~nm}$; Invitrogen Life Technologies) and dihydroethidium (DHE; Ex/Em=518/605 nm; Invitrogen Life Technologies) as previously described $(25,27)$. DHE is highly selective for $\mathrm{O}_{2}{ }^{-}$among ROS. In brief, $1 \times 10^{6}$ cells in a $60-\mathrm{mm}$ culture dish were incubated with the designated doses of PX-12 for $72 \mathrm{~h}$ with or without $15 \mu \mathrm{M}$ each caspase inhibitor, $2 \mathrm{mM}$ NAC or $10 \mu \mathrm{M}$ BSO. Cells were then washed in PBS and incubated with $20 \mu \mathrm{M} \mathrm{H}_{2}$ DCFDA or DHE at $37^{\circ} \mathrm{C}$ for $30 \mathrm{~min} . \mathrm{H}_{2} \mathrm{DCFDA}$ or DHE fluorescence was assessed 
A

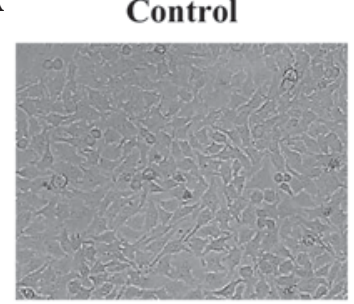

$1 \mu \mathrm{M}$ PX-12

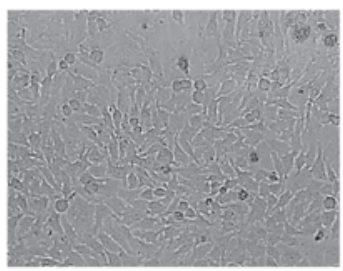

B

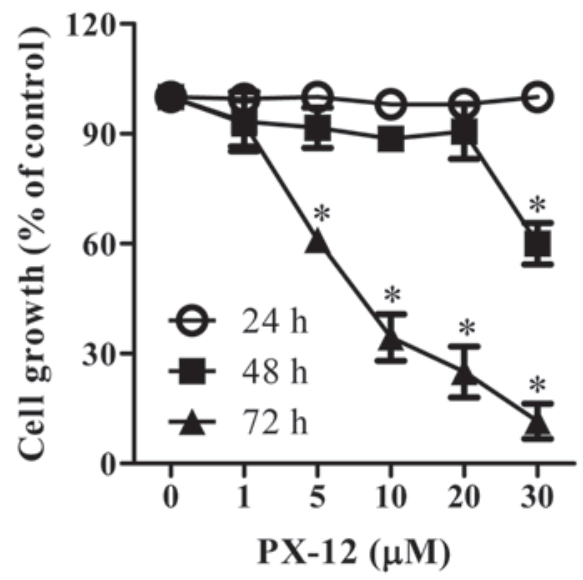

$5 \mu \mathrm{M}$ PX-12
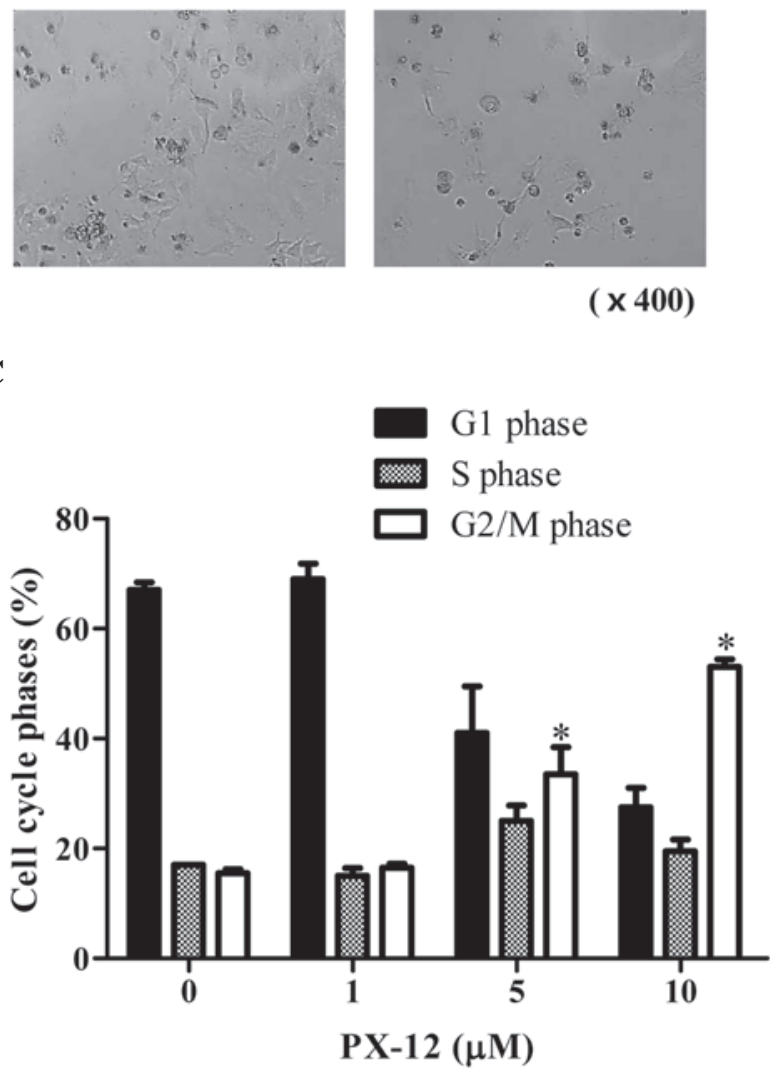

Figure 1. Effects of PX-12 on cell growth and cell cycle distribution in HeLa cells. Exponentially growing cells were treated with the indicated concentrations of PX-12 for the indicated time points. (A) Figures indicate cell population in PX-12-treated HeLa cells at $72 \mathrm{~h}$. (B) Cellular growth changes in HeLa cells as assessed by MTT assays. (C) Changes in the cell cycle distributions as assessed by DNA flow cytometric analysis at $72 \mathrm{~h}$. "P<0.05, compared with the control group. MTT, 3-(4,5-dimethylthiazol-2-yl)-2,5-diphenyltetrazolium bromide.
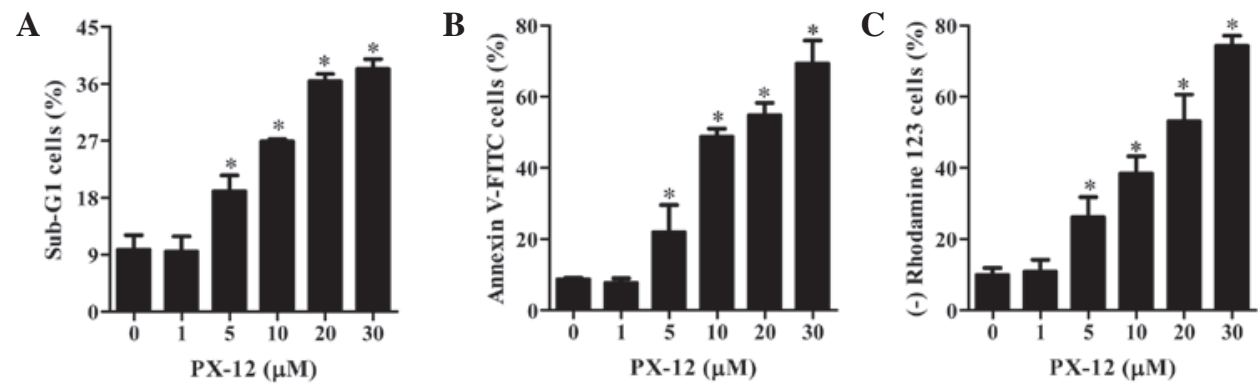

Figure 2. Effects of PX-12 on cell death and MMP in HeLa cells. Exponentially growing cells were treated with the indicated concentrations of PX-12 for $72 \mathrm{~h}$. Percentages of (A) sub-G1 cells and (B) annexin V-positive cells as measured by FACStar flow cytometry. (C) The percentage of rhodamine 123-negative (loss of MMP) cells as measured by FACStar flow cytometry. "P $<0.05$, compared with the control group. MMP, mitochondrial membrane potential; FITC, fluorescein isothiocyanate.

using the FACStar flow cytometer. ROS and $\mathrm{O}_{2}{ }^{--}$levels were expressed as mean fluorescence intensity, which was calculated by CellQuest software (Becton Dickinson).

Detection of intracellular GSH. Intracellular GSH levels were analyzed using a 5-chloromethylfluorescein diacetate $(\mathrm{CMFDA})$ dye $(\mathrm{Ex} / \mathrm{Em}=522 / 595 \mathrm{~nm}$; Invitrogen Life Technologies) as previously described $(27,28)$. In brief, $1 \times 10^{6}$ cells in a $60-\mathrm{mm}$ culture dish were incubated with the designated doses of PX-12 for $72 \mathrm{~h}$ with or without $15 \mu \mathrm{M}$ each caspase inhibitor, $2 \mathrm{mM}$ NAC or $10 \mu \mathrm{M}$ BSO. Cells were then washed with PBS and incubated with $5 \mu \mathrm{M}$ CMFDA at $37^{\circ} \mathrm{C}$ for $30 \mathrm{~min}$. CMFDA fluorescence intensity was determined using the FACStar flow cytometer. Negative CMFDA staining (GSH-depletion) of cells was expressed as the percentage of CMFDA-negative cells.

Statistical analysis. Results represent the mean of at least three independent experiments (mean \pm standard deviation). Data were analyzed using Instat software (GraphPad Prism 4, San Diego, CA, USA). Student's t-test or one-way analysis of variance with post hoc analysis using Tukey's multiple 
A

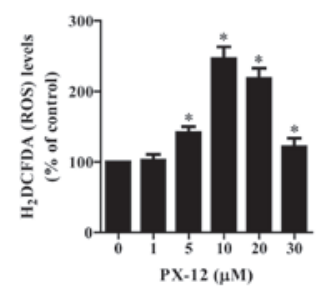

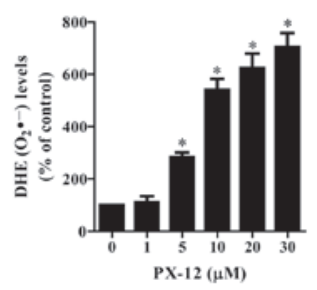

C

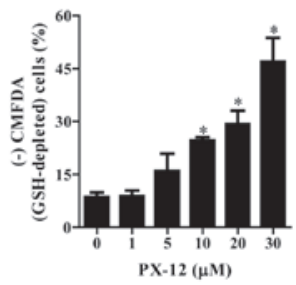

Figure 3. Effects of PX-12 on the intracellular ROS and GSH levels in HeLa cells. Exponentially growing cells were treated with the indicated concentrations of PX-12 for $72 \mathrm{~h}$. ROS and GSH levels in HeLa cells were measured using a FACStar flow cytometer. (A) $\mathrm{H}_{2}$ DCFDA (ROS) levels and (B) DHE (O $\left.{ }_{2}^{\circ}\right)$ levels as a percentage of the control. (C) The percentage of CMFDA-negative (GSH-depleted) cells. " $\mathrm{P}<0.05$, compared with the control group. ROS, reactive oxygen species; GSH, glutathione; $\mathrm{H}_{2}$ DCFDA, 2',7'-dichlorodihydrofluorescein diacetate; DHE, dihydroethidium; CMFDA, 5-chloromethylfluorescein diacetate.

A

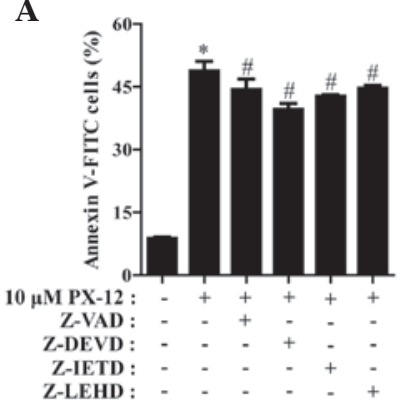

C

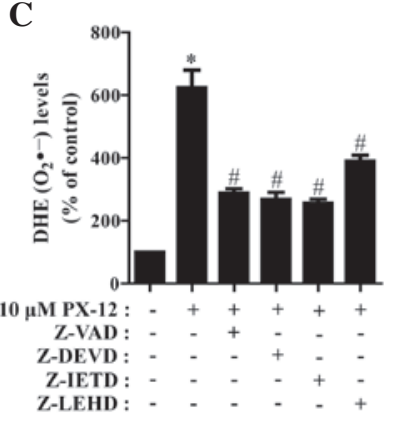

B

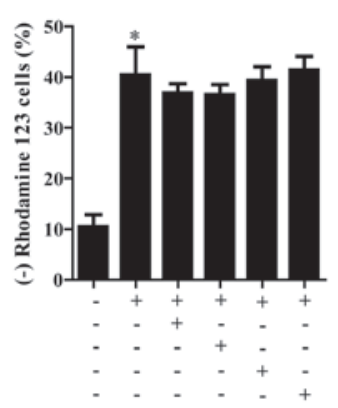

D

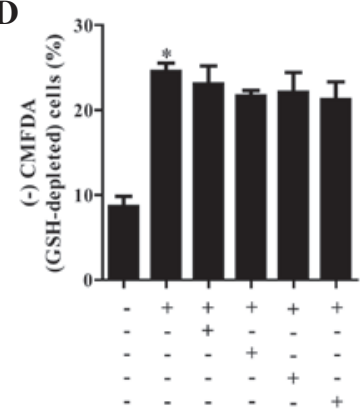

Figure 4. Effects of caspase inhibitors on cell death, MMP, $\mathrm{O}_{2}{ }^{-}$and GSH levels in PX-12-treated HeLa cells. Exponentially growing cells were treated with $10 \mu \mathrm{M}$ PX-12 for $72 \mathrm{~h}$ following $1 \mathrm{~h}$ pre-incubation with $15 \mu \mathrm{M}$ each caspase inhibitor. The number of annexin V/PI-stained cells, as well as MMP, $\mathrm{O}_{2}{ }^{-}$and GSH levels in HeLa cells were measured using a FACStar flow cytometer. Percentage of (A) annexin V-positive cells, (B) rhodamine 123-negative (loss of MMP) cells, (C) $\mathrm{O}_{2}{ }^{--}$(DHE) levels and (D) CMFDA-negative (GSH-depleted) cells. " $\mathrm{P}<0.05$, compared with the control group; ${ }^{\text {P }}<0.05$, compared with cells treated with PX-12 only. MMP, mitochondrial membrane potential; GSH, glutathione; PI, propidium iodide; DHE, dihydroethidium; CMFDA, 5-chloromethylfluorescein diacetate.

comparison test were used for parametric data. $\mathrm{P}<0.05$ was considered to indicate a statistically significant difference.

\section{Results}

Effects of PX-12 on cell growth and cell cycle distribution in HeLa cells. We first examined the effect of PX-12 on the growth of HeLa cells. After exposure to 1-10 $\mu \mathrm{M}$ PX-12 for $72 \mathrm{~h}$, the population of HeLa cells was not affected at $1 \mu \mathrm{M}$ PX-12, whereas the population of these cells was markedly decreased at 5-10 $\mu \mathrm{M}$ PX-12 (Fig. 1A). In addition, 5 and $10 \mu \mathrm{M}$ PX-12 treatment induced cell death in HeLa cells (Fig. 1A). Based on

MTT assays, the tested doses (1-30 $\mu \mathrm{M})$ of PX-12 did not affect changes in cell growth at $24 \mathrm{~h}$, whereas a high dose of $30 \mu \mathrm{M}$ PX-12 significantly decreased the growth of HeLa cell at $48 \mathrm{~h}$ (Fig. 1B). At $72 \mathrm{~h}, 5-30 \mu \mathrm{M}$ PX-12 significantly inhibited the growth of HeLa cells with an $\mathrm{IC}_{50}$ value (the half maximal inhibitory concentration) of $\sim 7 \mu \mathrm{M}$ at $72 \mathrm{~h}$ (Fig. 1B). When the cell cycle distributions were examined in PX-12-treated HeLa cells, 5 and $10 \mu \mathrm{M}$ PX-12 significantly induced a G2/M phase arrest of the cell cycle at $72 \mathrm{~h}$ (Fig. 1C).

Effects of PX-12 on cell death and MMP in HeLa cells. As shown in Fig. 2A, PX-12 increased the percentages of sub-G1 cells in a dose-dependent manner at $72 \mathrm{~h}$. Treatment with 5-30 $\mu \mathrm{M}$ PX-12 increased the number of annexin V-FITC-positive cells, whereas $1 \mu \mathrm{M}$ PX-12 did not increase the percentage of annexin V-FITC-positive cells (Fig. 2B). Cell death is closely associated with the collapse of MMP (29). As expected, the loss of MMP was observed in PX-12-treated HeLa cells (Fig. 2C). This result indicates that PX-12 damaged the membrane of mitochondria in HeLa cells.

Effects of PX-12 on ROS and GSH levels in HeLa cells. To assess the intracellular ROS levels in PX-12-treated HeLa cells, we used $\mathrm{H}_{2}$ DCFDA and DHE dyes. As shown in Fig. 3A, PX-12 significantly increased the intracellular ROS $\left(\mathrm{H}_{2} \mathrm{DCFDA}\right)$ levels in HeLa cells at $72 \mathrm{~h}$. Among the tested concentrations, $10 \mu \mathrm{M}$ PX-12 led to the maximum level of ROS $\left(\mathrm{H}_{2}\right.$ DCFDA) (Fig. 3A). Moreover, red fluorescence derived from DHE reflecting the intracellular $\mathrm{O}_{2}{ }^{-*}$ levels was markedly increased in PX-12-treated HeLa cells at $72 \mathrm{~h}$ (Fig. 3B). When intracellular GSH levels were measured in PX-12-treated HeLa cells using a CMFDA dye, 10-30 $\mu$ M PX-12 significantly increased the number of GSH-depleted cells at $72 \mathrm{~h}$; however, $5 \mu \mathrm{M}$ PX-12 marginally induced GSH depletion (Fig. 3C).

Effects of caspase inhibitors on cell death, $M M P, \mathrm{O}_{2}{ }^{-*}$ and GSH levels in PX-12-treated HeLa cells. We determined which caspases were involved in HeLa cell death caused by PX-12. For this experiment, we selected $10 \mu \mathrm{M}$ PX-12 as a suitable dose to differentiate the levels of cell death in the presence or absence of each caspase inhibitor. Based on a previous study (21), HeLa cells were pretreated with $15 \mu \mathrm{M}$ caspase inhibitor for $1 \mathrm{~h}$ prior to treatment with PX-12. This dose did not significantly affect cell death in the control HeLa cells (data not shown). Treatment with all the tested caspase inhibitors (Z-VAD for pan-caspases, Z-DEVD for caspase-3, Z-IETD for caspase-8 and Z-LEHD 
A
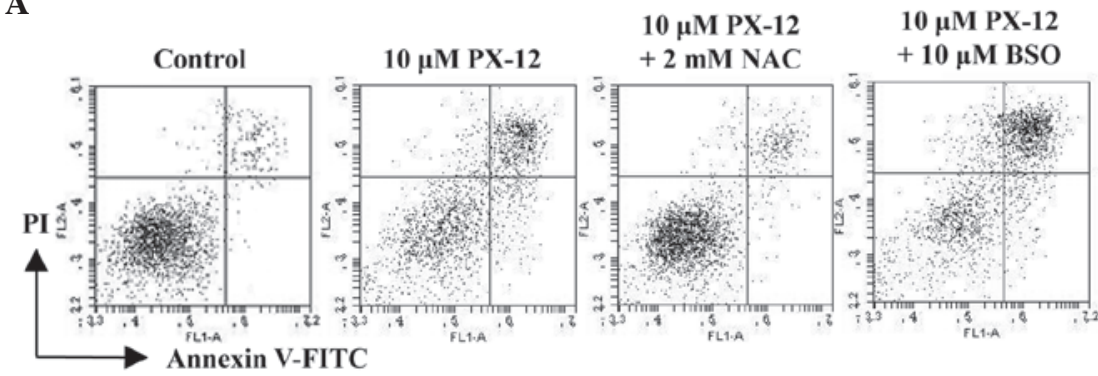
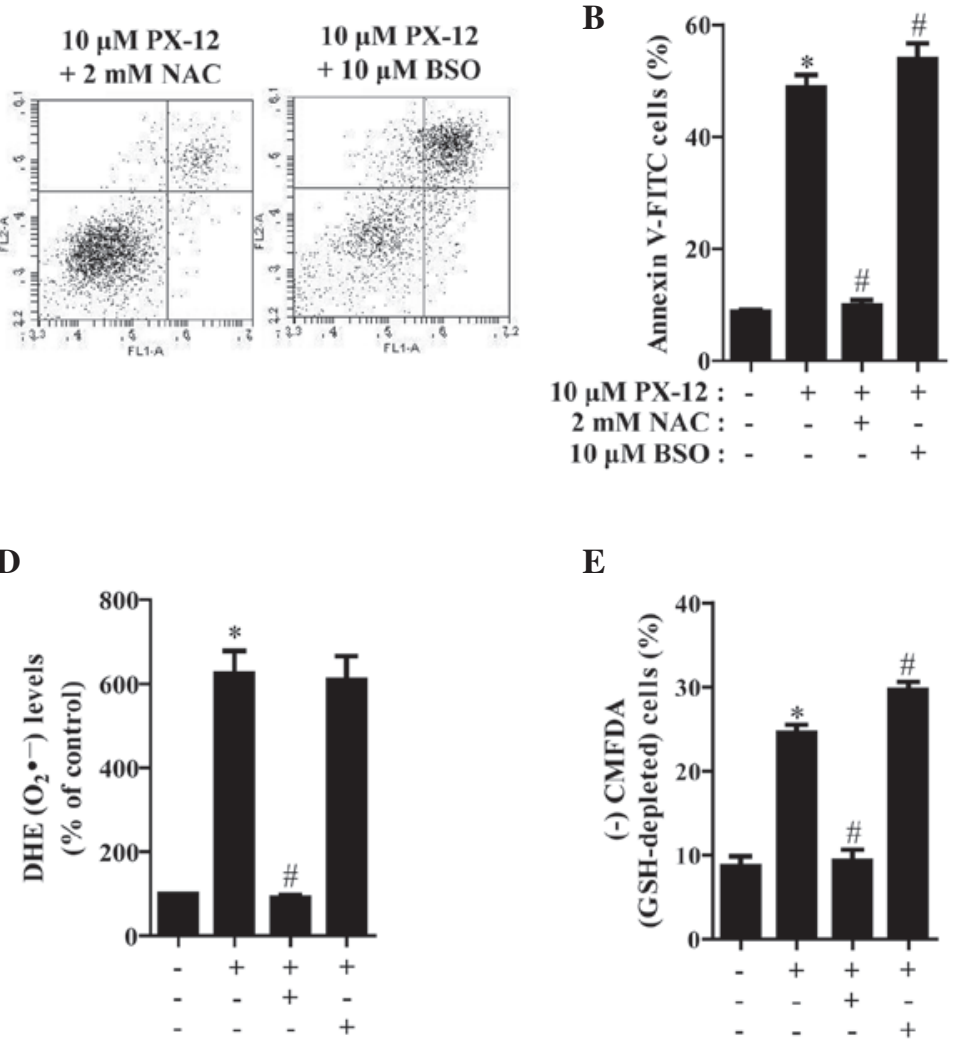

$\mathbf{E}$

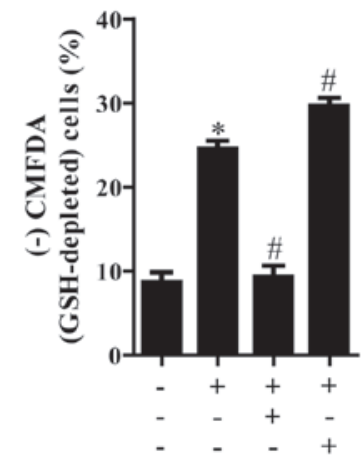

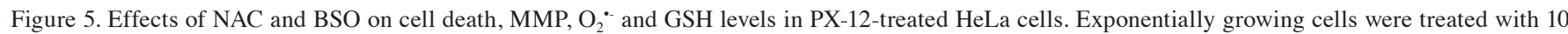
$\mu \mathrm{M}$ PX-12 for $72 \mathrm{~h}$ following $1 \mathrm{~h}$ pre-incubation with $2 \mathrm{mM} \mathrm{NAC}$ or $10 \mu \mathrm{M}$ BSO. The number of annexin V/PI-stained cells, as well as MMP, ${ }_{2}{ }^{-}$and GSH levels in HeLa cells were measured using a FACStar flow cytometer. (A) Each figure shows a representative for annexin V and/or PI stained cells. (B) The graph shows the percentage of annexin V-positive cells from A. (C) The graph shows the percentage of rhodamine 123-negative (loss of MMP) cells. (D and E) The graphs indicate $\mathrm{O}_{2}^{-}$(DHE) levels as a percentage of the control (D) and the percentage of CMFDA-negative (GSH-depleted) cells (E). ${ }^{*} \mathrm{P}<0.05$, compared with the control group; ${ }^{*} \mathrm{P}<0.05$, compared with cells treated with PX-12 only. NAC, N-acetyl cysteine; BSO, L-buthionine sulfoximine; MMP, mitochondrial membrane potential; GSH, glutathione; PI, propidium iodide; DHE, dihydroethidium; CMFDA, 5-chloromethylfluorescein diacetate.

for caspase-9) demonstrated the significant rescue of HeLa cells from PX-12-induced apoptosis at $72 \mathrm{~h}$, as measured by the population of annexin V-FITC-positive cells (Fig. 4A). In addition, all the caspase inhibitors marginally, but not significantly, prevented the loss of MMP caused by PX-12 (Fig. 4B).

It was also investigated whether the levels of intracellular $\mathrm{O}_{2}{ }^{--}$and GSH in PX-12-treated HeLa cells were affected by treatment with each caspase inhibitor. As shown in Fig. 4C, all the caspase inhibitors significantly decreased $\mathrm{O}_{2}{ }^{-}$levels in PX-12-treated HeLa cells. Moreover, these caspase inhibitors marginally prevented GSH depletion in these cells (Fig. 4D).

Effects of NAC and BSO on cell death, MMP, $\mathrm{O}_{2}{ }^{--}$and GSH levels in PX-12-treated HeLa cells. The effects of NAC or BSO on cell death and MMP in $10 \mu \mathrm{M}$ PX-12-treated HeLa cells were assessed at 72 h. As shown in Fig. 5A and B, NAC significantly decreased the number of annexin V-FITC-positive cells in the PX-12-treated HeLa cell population, whereas BSO increased the number of these cells. NAC and BSO did not significantly affect cell growth and cell death in the control HeLa cells (data not shown). With respect to MMP, NAC significantly attenuated the loss of MMP caused by PX-12 whereas BSO enhanced, to a certain extent, the loss in these cells (Fig. 5C). Furthermore, it was determined whether the levels of intracellular $\mathrm{O}_{2}{ }^{-}$and GSH in PX-12-treated HeLa cells were affected by treatment with NAC or BSO. While NAC markedly decreased the level of $\mathrm{O}_{2}{ }^{-}$in PX-12-treated HeLa cells, BSO had no effect on the level of $\mathrm{O}_{2}{ }^{-}$in these cells (Fig. 5D). With regard to GSH levels, NAC markedly prevented GSH depletion caused by PX-12, whereas BSO intensified GSH depletion in these cells (Fig. 5E).

\section{Discussion}

The aim of the present study was to assess the effects of PX-12 on cell growth and death in HeLa cells in association with ROS and GSH levels. Following exposure to PX-12 for $72 \mathrm{~h}$, the $\mathrm{IC}_{50}$ value in HeLa cells was $\sim 7 \mu \mathrm{M}$ based on MTT assays. However, the tested doses of PX-12 did not show the growth inhibition of HeLa cells at $24 \mathrm{~h}$ and this effect was mild at $48 \mathrm{~h}$. Therefore, the susceptibility of HeLa cells to PX-12 appeared to significantly increase after the incubation time of $48 \mathrm{~h}$. DNA flow cytometric analysis indicated that 5 and $10 \mu \mathrm{M}$ significantly induced a G2/M phase arrest of the cell cycle. As 20 and $30 \mu \mathrm{M}$ PX-12 completely decreased cell growth, it was not possible to perform cell cycle analysis in HeLa cells. Similarly, PX-12 induced a G2/M phase arrest in B-cell lymphoma and breast cancer cells $(7,30)$. We also observed that PX-12 induced a G2/M phase arrest in A549 and Calu-6 lung cancer cells (unpublished data). Therefore, the G2/M phase arrest in PX-12-treated cells was an underlying mechanism to suppress the growth of cancer cells, including HeLa cells. 
PX-12 also increased the number of dead cells and annexin V-FITC-positive cells at $72 \mathrm{~h}$, suggesting that PX-12-induced HeLa cell death occurred via apoptosis. Apoptosis is closely associated with the collapse of MMP (31). Our results demonstrated that PX-12 triggered the loss of MMP in HeLa cells in a dose-dependent manner. Furthermore, treatment with the caspase inhibitors investigated in this experiment significantly prevented HeLa cell death caused by PX-12. In particular, the caspase- 8 inhibitor attenuated HeLa cell death. These data suggest that the mitochondrial pathway and cell death receptor pathway are together necessary for the complete induction of apoptosis in PX-12-treated HeLa cells. However, all the caspase inhibitors marginally, but not significantly prevented the loss of MMP caused by PX-12. These results implied that the loss of MMP by PX-12 may not be enough to fully induce apoptosis in HeLa cells under the inhibition of caspases by their inhibitors.

PX-12, as an inhibitor of Trx-1, increases ROS levels. It has been reported that PX-12 induces oxidative stress (32). Similarly, in the present study, the intracellular ROS levels, particularly those of $\mathrm{O}_{2}{ }^{--}$, were significantly increased in PX-12-treated HeLa cells at 72 h. All caspase inhibitors demonstrating anti-apoptotic effects decreased the level of $\mathrm{O}_{2}{ }^{-}$. These data indicated that the level of $\mathrm{O}_{2}{ }^{-}$, among other ROS, is closely associated with apoptosis in PX-12-treated HeLa cells. Furthermore, NAC markedly prevented apoptotic cell death and the loss of MMP in PX-12-treated HeLa cells, accompanied by strongly decreasing $\mathrm{O}_{2}{ }^{-}$levels in these cells. Overall, these results suggest that PX-12-induced cell death is mediated by oxidative stress. GSH is an important intracellular antioxidant that protects cells from damage caused by free radicals, peroxides and toxins. It is able to remove $\mathrm{O}_{2}{ }^{--}$and provide electrons for glutathione peroxidase to reduce $\mathrm{H}_{2} \mathrm{O}_{2}$ to $\mathrm{H}_{2} \mathrm{O}$. Apoptotic effects are inversely comparative to $\mathrm{GSH}$ content (33-35). In the current study, PX-12 increased the percentages of GSH-depleted cells at $72 \mathrm{~h}$. NAC markedly prevented the depletion of GSH in PX-12-treated HeLa cells. Furthermore, BSO, which augmented apoptotic cell death and the loss of MMP in PX-12-treated HeLa cells, increased GSH depletion in these cells. These results support the hypothesis that the intracellular GSH content has a decisive effect on cell death $(26,28,34)$. However, in the present study, caspase inhibitors marginally prevented GSH depletion in PX-12-treated HeLa cells. Therefore, the loss of GSH content appeared to be necessary, but not sufficient to fully induce apoptosis in PX-12-treated HeLa cells.

In conclusion, to the best of our knowledge, this is the first study to demonstrate that PX-12 inhibits the growth of HeLa cells via G2/M phase arrest, as well as apoptosis. This toxicological effect was associated with intracellular increases in ROS levels and GSH depletion. The present study provides an important insight into the toxicological effects of PX-12 on HeLa cells with respect to ROS and GSH levels.

\section{Acknowledgements}

This study was supported by the National Research Foundation of Korea grant funded by the Korea government (MSIP) (no. 2008-0062279) and research funds of Chonbuk National University in 2013.

\section{References}

1. Shi Y, Tang B, Yu PW, Tang B, Hao YX, Lei X, Luo HX and Zeng DZ: Autophagy protects against oxaliplatin-induced cell death via ER stress and ROS in Caco-2 cells. PLoS One 7: e51076, 2012

2. Gonzalez C, Sanz-Alfayate G, Agapito MT, Gomez-Nino A, Rocher A and Obeso A: Significance of ROS in oxygen sensing in cell systems with sensitivity to physiological hypoxia. Respir Physiol Neurobiol 132: 17-41, 2002.

3. Baran CP, Zeigler MM, Tridandapani S and Marsh CB: The role of ROS and RNS in regulating life and death of blood monocytes. Curr Pharm Des 10: 855-866, 2004.

4. Zorov DB, Juhaszova $M$ and Sollott SJ: Mitochondrial ROS-induced ROS release: an update and review. Biochim Biophys Acta 1757: 509-517, 2006.

5. Lo YL, Wang W and Ho CT: 7,3',4'-Trihydroxyisoflavone modulates multidrug resistance transporters and induces apoptosis via production of reactive oxygen species. Toxicology 302: 221-232, 2012.

6. Bell EL, Emerling BM, Ricoult SJ and Guarente L: SirT3 suppresses hypoxia inducible factor $1 \alpha$ and tumor growth by inhibiting mitochondrial ROS production. Oncogene 30: 2986-2996, 2011

7. Li C, Thompson MA, Tamayo AT, Zuo Z, Lee J, Vega F, Ford RJ and Pham LV: Over-expression of Thioredoxin-1 mediates growth, survival, and chemoresistance and is a druggable target in diffuse large B-cell lymphoma. Oncotarget 3: 314-326, 2012.

8. Lim JY, Yoon SO, Hong SW, Kim JW, Choi SH and Cho JY: Thioredoxin and thioredoxin-interacting protein as prognostic markers for gastric cancer recurrence. World J Gastroenterol 18: 5581-5588, 2012

9. Yang J, Li C, Ding L, Guo Q, You Q and Jin S: Gambogic acid deactivates cytosolic and mitochondrial thioredoxins by covalent binding to the functional domain. J Nat Prod 75: 1108-1116, 2012.

10. Chae JS, Gil Hwang S, Lim DS and Choi EJ: Thioredoxin-1 functions as a molecular switch regulating the oxidative stress-induced activation of MST1. Free Radic Biol Med 53: 2335-2343, 2012 .

11. Ungerstedt J, Du Y, Zhang H, Nair D and Holmgren A: In vivo redox state of human thioredoxin and redox shift by the histone deacetylase inhibitor suberoylanilide hydroxamic acid (SAHA). Free Radic Biol Med 53: 2002-2007, 2012.

12. Wang Y, Lu H, Wang D, Li S, Sun K, Wan X, Taylor EW and Zhang J: Inhibition of glutathione synthesis eliminates the adaptive response of ascitic hepatoma 22 cells to nedaplatin that targets thioredoxin reductase. Toxicol Appl Pharmacol 265: 342-350, 2012.

13. Samuel SM, Thirunavukkarasu M, Penumathsa SV, Koneru S, Zhan L, Maulik G, Sudhakaran PR and Maulik N: Thioredoxin-1 gene therapy enhances angiogenic signaling and reduces ventricular remodeling in infarcted myocardium of diabetic rats. Circulation 121: 1244-1255, 2010.

14. Fath MA, Ahmad IM, Smith CJ, Spence J and Spitz DR: Enhancement of carboplatin-mediated lung cancer cell killing by simultaneous disruption of glutathione and thioredoxin metabolism. Clin Cancer Res 17: 6206-6217, 2011.

15. Wondrak GT: Redox-directed cancer therapeutics: molecular mechanisms and opportunities. Antioxid Redox Signal 11: 3013-3069, 2009.

16. Welsh SJ, Williams RR, Birmingham A, Newman DJ, Kirkpatrick DL and Powis G: The thioredoxin redox inhibitors 1-methylpropyl 2-imidazolyl disulfide and pleurotin inhibit hypoxia-induced factor lalpha and vascular endothelial growth factor formation. Mol Cancer Ther 2: 235-243, 2003.

17. Mukherjee A and Martin SG: The thioredoxin system: a key target in tumour and endothelial cells. Br J Radiol 81 Spec No 1: S57-S68, 2008.

18. Baker AF, Adab KN, Raghunand N, Chow HH, Stratton SP, Squire SW, Boice M, Pestano LA, Kirkpatrick DL and Dragovich T: A phase IB trial of 24-hour intravenous PX-12, a thioredoxin-1 inhibitor, in patients with advanced gastrointestinal cancers. Invest New Drugs 31: 631-641 2012.

19. Ramanathan RK, Kirkpatrick DL, Belani CP, Friedland D, Green SB, Chow HH, Cordova CA, Stratton SP, Sharlow ER, Baker A and Dragovich T: A Phase I pharmacokinetic and pharmacodynamic study of PX-12, a novel inhibitor of thioredoxin-1, in patients with advanced solid tumors. Clin Cancer Res 13: 2109-2114, 2007. 
20. Hedley D, Pintilie M, Woo J, Nicklee T, Morrison A, Birle D, Fyles A, Milosevic M and Hill R: Up-regulation of the redox mediators thioredoxin and apurinic/apyrimidinic excision (APE)/Ref-1 in hypoxic microregions of invasive cervical carcinomas, mapped using multispectral, wide-field fluorescence image analysis. Am J Pathol 164: 557-565, 2004.

21. Han YH, Kim SZ, Kim SH and Park WH: Pyrogallol inhibits the growth of lung cancer Calu-6 cells via caspase-dependent apoptosis. Chem Biol Interact 177: 107-114, 2009.

22. Han YHand Park WH: The effects of $\mathrm{N}$-acetyl cysteine, buthionine sulfoximine, diethyldithiocarbamate or 3-amino-1,2,4-triazole on antimycin A-treated Calu-6 lung cells in relation to cell growth, reactive oxygen species and glutathione. Oncol Rep 22: 385-391, 2009.

23. Han YH, Moon HJ, You BR, Kim SZ, Kim SH and Park WH: Effects of carbonyl cyanide p-(trifluoromethoxy) phenylhydrazone on the growth inhibition in human pulmonary adenocarcinoma Calu-6 cells. Toxicology 265: 101-107, 2009.

24. Han YH, Kim SZ, Kim SH and Park WH: Pyrogallol inhibits the growth of human lung cancer Calu- 6 cells via arresting the cell cycle arrest. Toxicol In Vitro 22: 1605-1609, 2008.

25. Han YH, Moon HJ, You BR and Park WH: The effect of MG132, a proteasome inhibitor on HeLa cells in relation to cell growth, reactive oxygen species and GSH. Oncol Rep 22: 215-221, 2009.

26. Han YH, Kim SH, Kim SZ and Park WH: Carbonyl cyanide p-(trifluoromethoxy) phenylhydrazone (FCCP) as an $\mathrm{O} 2\left({ }^{*}-\right)$ generator induces apoptosis via the depletion of intracellular GSH contents in Calu-6 cells. Lung Cancer 63: 201-209, 2009.

27. Han YH and Park WH: Propyl gallate inhibits the growth of HeLa cells via regulating intracellular GSH level. Food Chem Toxicol 47: 2531-2538, 2009.
28. Han YH, Kim SZ, Kim SH and Park WH: Intracellular GSH level is a factor in As4.1 juxtaglomerular cell death by arsenic trioxide. J Cell Biochem 104: 995-1009, 2008.

29. Griffiths EJ: Mitochondria - potential role in cell life and death Cardiovasc Res 46: 24-27, 2000.

30. Vogt A, Tamura K, Watson S and Lazo JS: Antitumor imidazolyl disulfide IV-2 causes irreversible G(2)/M cell cycle arrest without hyperphosphorylation of cyclin-dependent kinase Cdk1. J Pharmacol Exp Ther 294: 1070-1075, 2000.

31. Yang J, Liu X, Bhalla K, Kim CN, Ibrado AM, Cai J, Peng TI, Jones DP and Wang X: Prevention of apoptosis by Bcl-2: release of cytochrome c from mitochondria blocked. Science 275: 1129-1132, 1997.

32. Lee YJ, Kim JH, Chen J and Song JJ: Enhancement of metabolic oxidative stress-induced cytotoxicity by the thioredoxin inhibitor 1-methylpropyl 2-imidazolyl disulfide is mediated through the ASK1-SEK1-JNK1 pathway. Mol Pharmacol 62: 1409-1417, 2002.

33. Han YH, Kim SZ, Kim SH and Park WH: Enhancement of arsenic trioxide-induced apoptosis in HeLa cells by diethyldithiocarbamate or buthionine sulfoximine. Int J Oncol 33: 205-213, 2008.

34. Estrela JM, Ortega A and Obrador E: Glutathione in cancer biology and therapy. Crit Rev Clin Lab Sci 43: 143-181, 2006.

35. Han YH, Kim SZ, Kim SH and Park WH: Suppression of arsenic trioxide-induced apoptosis in HeLa cells by $\mathrm{N}$-acetylcysteine. Mol Cells 26: 18-25, 2008. 